\title{
ANÁLISE DA VIABILIDADE DO DESENVOLVIMENTO DE CONCRETO AUTOCICATRIZANTE COM ADIÇÃO DE CINZA VOLANTE DO RIO GRANDE DO SUL
}

\author{
CONZATTI DE PAOLI, THAÍS ROZA \\ Graduanda em Engenharia Civil \\ Universidade do Vale do Rio dos Sinos \\ Rio Grande do Sul, Brazil \\ thaisdepaoli@yahoo.com.br
}

\author{
ZAMIS EHRENBRING, HINOEL \\ Doutorando em Engenharia Civil \\ Universidade do Vale do Rio dos Sinos \\ Rio Grande do Sul, Brazil \\ hzamis@unisinos.br
}

\author{
DOS REIS DA SILVA, NICOLAS \\ Engenheiro Civil \\ Universidade do Vale do Rio dos Sinos \\ Rio Grande do Sul, Brazil \\ nicosil_reis@hotmail.com \\ PACHECO, FERNANDA \\ Prof, doutoranda em Engenharia Civil \\ Universidade do Vale do Rio dos Sinos \\ Rio Grande do Sul, Brazil \\ fernandapache@unisinos.br
}

\section{RESUMO}

Para diminuir os problemas causados pelas fissuras e despesas de intervenções e até de retrabalho nos elementos de concreto armado, a autocicatrização de matrizes cimentícias tem sido amplamente estudada. Logo, este trabalho avaliou a colmatação de fissuras do concreto com adição pozolânica, no caso, a cinza volante. Foram moldados corpos de prova de concreto variando a adição de cinza volante, em massa, tendo sido as amostras expostas nas curas submersa em água, câmara úmida e seco em temperatura ambiente. Nos corpos de prova cilíndricos foram realizados ensaios de resistência à compressão, já nos prismáticos, foram provocadas fissuras através do ensaio de tração na flexão, onde analisou-se a influência das diferentes condições de cura sobre cada traço no fechamento das fissuras. As amostras com adição de $25 \%$ possuíram os maiores ganhos de resistência. Os melhores resultados no percentual de cicatrização foram na cura submersa. A cicatrização máxima apresentou espessura de $0,15 \mathrm{~mm}$.

Palavras-chave: concreto autocicatrizante, fissuração, cinza volante, pozolanas, durabilidade.

\begin{abstract}
To reduce problems caused by cracking and expense of interventions and even rework of reinforced concrete, the selfhealing of cementitious matrices has been widely studied. Therefore, this work evaluated the cracking of concrete with pozzolanic addition, in this case, fly ash. Concrete specimens were molded varying the addition of fly ash, by mass, and the samples were exposed in the cures submerged in water, humid chamber and dry at room temperature. In the cylindrical specimens, compressive strength tests were performed, while in the prismatic specimens, cracks were caused by the flexural tensile test, where the influence of different curing conditions in the crack closure was analyzed. The samples with 25\% addition had the highest strength gains. The best results in the healing percentage were in submerged cure. The maximum healing presented thickness of $0,15 \mathrm{~mm}$.
\end{abstract}

Keywords: self-healing concrete, cracking, fly ash, pozzolans, durability.

\section{INTRODUÇÃO}

O concreto, juntamente com o aço, formando o concreto armado, continua sendo o principal material empregado no meio construtivo devido a suas inúmeras vantagens (NEVILLE, 2016). O concreto convencional apresenta um bom comportamento à compressão, porém é frágil e tende a fissurar quando submetido às tensões de tração. Se não tratadas, essas fissuras podem provocar prejuízos à durabilidade da estrutura, pois é favorecida a entrada de agentes agressivos que deterioram o aço embutido na peça (BONIĆ et al., 2015). Há também as microfissuras na superfície do concreto, causando o aumento da permeabilidade do material, tornando-o vulnerável aos danos causados pelo intemperismo.

A durabilidade e vida útil das edificações são condicionantes de grande relevância, de modo que as construções sejam seguras e sustentáveis. Assim, quando há impacto nessas características há prejuízos técnicos e econômicos, assim como ecológicos e sustentáveis (TANG et. al 2015; VARLAMOV et al., 2017).

A deterioração precoce das estruturas é o resultado, geralmente, de problemas de projeto, execução, falta de manutenção e baixa qualidade dos materiais empregados. Cada material reage de uma maneira, variando assim, o tempo e a intensidade da deterioração em função das condições de exposição e do tipo de material envolvido (HAVLÁSEK et al., 2017; HALIQ; EHSAN, 2016).Constata-se que, já há algum tempo, os valores gastos com manutenções estão se 
equiparando aos gastos com novos empreendimentos, existindo casos em que os gastos com novas construções foram superados pelos gastos com reparos (HELENE, 2011), apontando para a pertinência no estudo de sistemas contrutivos e materiais mais duráveis (KRISHNAPRIYA, et al., 2015). O principal motivo de estudar materiais com propriedades autorregenerantes é o impacto na vida útil sem interferência externa (SANGADJI, 2017). Já se verificou uma propriedade de autocura do concreto, decorrente da hidratação tardia ou secundária do cimento não hidratado ou por carbonatação, uma vez que a água penetre na fissura e esteja disponível para ocorrência das reações químicas entre os compostos (AFIFUDIN et al., 2011; HUANG et al., 2016).

Uma das alternativas é o uso de adições pozolânicas. Nesse mecanismo, a hidratação tardia das pozolanas têm comportamento semelhante às partículas anidras de cimento, possibilitando a cicatrização (ALYOUSIF, 2016; GRUYAERT et al., 2014). Destaca-se, no entanto, que esse processo ocorre apenas quando ainda não houve a hidratação tardia das pozolanas, e então, se restringe praticamente às fissuras de retração, que ocorrem em idades iniciais. (TERMKHAJORNKIT et al, 2009) Uma das vantagens desse método é que não há exigências de uso de materiais especiais, não impactando no custo dos elementos de concreto. Além disso, sua aplicação é viável na situação real da indústria da construção civil. Cabe ser citado o benefício em relação ao menor impacto ambiental, visto que as pozolanas são resíduos oriundos de outros processos e indústrias (GJORV, 2011).

A finura dos materiais pozolânicos aumenta a compacidade da matriz, logo, o desempenho mecânico, durabilidade e vida útil de estruturas de concreto também tendem a crescer. Ao utilizar pozolanas, há uma alteração na microestrutura e na zona de transição do concreto, diminuindo o tamanho dos poros devido a hidratação secundária do silicato de cálcio (C-S-H) e ao tamanho das partículas, dificultando a penetração de água (LIU et al. 2014; MEHTA, MONTEIRO, 2014).

Para análise da eficiência dos componentes de auto cura do concreto, Flores et al (2015) utilizaram quatro formas de cura, são elas: imersão em água, contato com água, câmara úmida e exposição ao ar, fazendo comparação entre elas. Nos testes realizados, obteve-se melhores resultados com a cura de imersão em água, seguido da cura com contato com água. A pior condição de cura foi a seca. Assim, esse estudo avaliou a eficácia do mecanismo de autocura em concretos com a adição de cinza volante utilizando diferentes tipos de cura. Analisou-se, a partir de um traço inicial, variações no percentual de uso de cinza volante e do tipo de cura das amostras.

\section{MATERIAIS E MÉTODOS}

O programa experimental foi dividido em três etapas: definição do traço e caracterização do concreto no estado fresco, caracterização do concreto no estado endurecido e ensaio de tração na flexão para fissuração, e, posteriormente, análise para validação da cicatrização. Os traços das amostras foram definidos conforme a NBR 6118 (ABNT, 2014) para a classe de agressividade ambiental II (CAA II). Tais parâmetros foram escolhidos devido às condições da região da pesquisa e o tamanho permitido de fissuração no seu estado limite de serviço, coerentes com o potencial resultado do uso de adições pozolânicas no concreto.

Foram moldados corpos de prova cilíndricos, de $200 \mathrm{~mm}$ de altura por $100 \mathrm{~mm}$ de diâmetro, para os ensaios de compressão axial, e corpos de prova prismáticos, de $60 \mathrm{~mm}$ de altura por $60 \mathrm{~mm}$ de largura e $180 \mathrm{~mm}$ de comprimento, para provocação de fissuras e ensaios de velocidade de propagação de ondas ultrassônicas, microscópio óptico para registro de imagens e análises fotográficas. Os processos de moldagem e cura dos corpos de prova foram executados conforme as normas NBR 5738 (ABNT, 2015) e NBR 9479 (ABNT, 2006), respectivamente. Antes da moldagem dos corpos de prova, foi realizado o ensaio de abatimento do tronco cone, verificando a consistência do concreto.

Após as moldagens, os corpos de prova cilindricos foram armazenados em câmara úmida até a data do ensaio de resistência à compressão axial, que ocorreu nas idades de 7, 28 e 56 dias. Neste ensaio, foram ensaiados três corpos de prova por traço, para cada idade de ensaio. Já os corpos de prova prismáticos foram colocados, após a moldagem, em cura submersa até os 28 dias. Após esse período, as amostras foram submetidas ao ensaio de flexão, com o objetivo de provocar a fissuração da amostra, controlando a carga, sem rompê-la, com dimensão de até 0,3 mm de abertura. Com base no ensaio de resistência a tração, foi feita uma adaptação, de aproximação dos apoios, de forma que o corpo de prova fissurasse e não se rompesse com facilidade. Na Figura 1 consta o método de realização do ensaio de provocação de fissura. Após fissuradas, as amostras foram encaminhadas para três tipos de cura: submersa em água, câmara úmida e a temperatura ambiente. Para a condição seca, as amostras foram mantidas em ambiente laboratorial, ao abrigo da luz. Para câmara úmida foram inseridas em câmara com temperatura e umidade de $23^{\circ} \mathrm{C}$ e $95 \%$, respectivamente. Para a cura submersa empregou-se a mesma câmara, porém, com a submersão em água. 


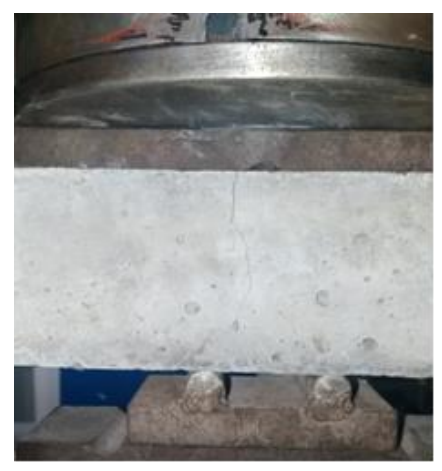

Figura 1: Método utilizado para o ensaio de provocação de fissura.

Foram moldados três corpos de prova por traço, para cada tipo de cura. O resumo da amostragem está demonstrado na Tabela 1.

Tabela 1 - Amostragem

\begin{tabular}{|c|c|c|c|c|c|c|}
\hline \multirow{2}{*}{$\begin{array}{c}\text { Teor de Adição } \\
\text { de Cinza }\end{array}$} & \multicolumn{3}{|c|}{ Cilíndrico } & \multicolumn{3}{c|}{ Prismáticos } \\
\cline { 2 - 7 } Volante & \multicolumn{2}{|c|}{ Ensaio de Compressão Axial } & \multicolumn{3}{c|}{ Cura/Ultrassom } \\
\cline { 2 - 7 } & 7 dias & 28 dias & 56 dias & Seca & Úmida & Submersa \\
\hline $0 \%$ & 3 & 3 & 3 & 3 & 3 & 3 \\
\hline $5 \%$ & 3 & 3 & 3 & 3 & 3 & 3 \\
\hline $15 \%$ & 3 & 3 & 3 & 3 & 3 & 3 \\
\hline $25 \%$ & 3 & 3 & 3 & 3 & 3 & 3 \\
\hline
\end{tabular}

Fonte: Elaborado pelos autores

O tipo de cimento utilizado foi o CP V - ARI, cimento Portland de alta resistência inicial. Foi utilizado agregado miúdo proveniente de areia extraída de rios, localizados na região do Vale dos Sinos/RS. O agregado graúdo escolhido foi a brita de origem basáltica. A cinza volante utilizada nas misturas é proveniente da queima de carvão mineral em usina termoelétrica. A massa específica obtida foi de $2,0018 \mathrm{~g} / \mathrm{cm}^{3}$. A área superficial obtida foi de $0.4737 \mathrm{~m} / \mathrm{g}$. Os diâmetros

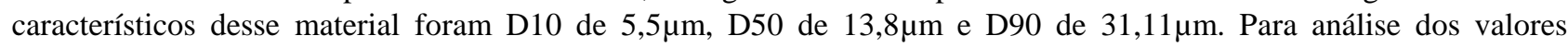
obtidos, pode-se citar outros valores já apontados em bibliografia, conforme consta a seguir: (a) Massa específica de $2,3 \mathrm{~g} / \mathrm{cm}^{3}$ e área superficial de 0,580 $\mathrm{m}^{2} / \mathrm{g}$ (LENG; FENG; LU, 2000), (b) massa específica de $2,6 \mathrm{~g} / \mathrm{cm}^{3}$ (SANKAVANARAYANNAN; JAGADESAN, 2016) e massa específica de $2,4 \mathrm{~g} / \mathrm{cm}^{3}$ e área superficial de $0,35 \mathrm{~m}^{2} / \mathrm{g}$ (KUMAR; TIKE; NANDA, 2007);

O traço de dosagem foi definido conforme Barboza e Bastos (2008). Sabendo disso, foi definida uma resistência de 30 $\mathrm{MPa}$, compatível com a classe adotada para este estudo. Foi definido o traço 1:2,9:2,95 com relação água/cimento de 0,65 . Nestes valores foram acrescidos os percentuais de cinza volante: $0 \%, 5 \%, 15 \%$ e $25 \%$, resultando em quatro traços diferentes.

Os ensaios de resistência à compressão axial foram realizados conforme a norma NBR 5739 (ABNT, 2018) para verificação do acréscimo de resistência que a cinza volante pode agregar ao concreto. Para este ensaio, foram utilizadas 9 amostras por tipo de traço, as quais se dividiram em três grupos de três amostras, para realização de ensaios de resistência à compressão nas idades de: 7, 28 e 56 dias. Os ensaios de velocidade de propagação de ondas ultrassônicas seguiram a norma IS 13311-92 - parte 1 e foram realizados para verificação do fechamento das fissuras, analisando a velocidade de propagação de ondas ultrassônicas. Esse ensaio foi realizado após 7 dias e 28 dias, a contar do ensaio de fissuração. Para a análise dos resultados de autocicatrização do concreto, foram utilizadas fotos tiradas das amostras prismáticas logo após os ensaios de ultrassom, a fim de fazer comparação dos tamanhos de fissuras. Essas fissuras, através das imagens, foram mensuradas em software de representaço gráfica. Foram obtidas imagens em microscópio ótico do laboratório de metalografia da Unisinos, o Galileo AV300+. As idades utilizadas para as imagens foram 7, 28 e 120 dias após a fissuração. 


\section{RESULTADOS}

Referente aos ensaios realizados de caracterização dos materiais, resistência à compressão, ultrassom, microscópio de medição ótica e registros fotográficos, avaliou-se as variações dos resultados em relação aos diferentes teores de cinza volante, tempos e tipos de cura das amostras, conforme apresentam os próximos itens.

\subsection{Ensaios de Abatimento de Troco de Cone}

Os resultados do ensaio de abatimento de tronco de cone estão apresentados na Tabela 2, separados por traço.

Tabela 2 - Resultados do ensaio de abatimento de tronco de cone ( $\mathrm{mm}$ )

\begin{tabular}{|c|c|c|c|c|}
\hline $\begin{array}{c}\text { Traço (percentual de } \\
\text { uso de cinza volante) }\end{array}$ & $0 \%$ & $5 \%$ & $15 \%$ & $25 \%$ \\
\hline $\begin{array}{c}\text { Abatimento de tronco } \\
\text { de cone (mm) }\end{array}$ & 90 & 80 & 90 & 70 \\
\hline
\end{tabular}

Fonte: Elaborado pelos autores

Percebe-se, que apesar das adições de cinza volante, o abatimento verificado se manteve muito próximo do traço referência. Todos os traços foram classificados conforme a NBR 7212 (ABNT, 2012) como S50.

\subsection{Ensaios de Resistência à Compressão Axial}

Os resultados dos ensaios à compressão axial estão apresentados na Tabela 3, para cada traço e idade de ensaio, destacando sua média aritmética.

Tabela 3 - Resultados de Ensaio de Compressão Axial

\begin{tabular}{|c|c|c|c|c|c|c|c|c|c|}
\hline \multirow[b]{2}{*}{ Traço } & \multicolumn{3}{|c|}{7 dias } & \multicolumn{3}{|c|}{28 dias } & \multicolumn{3}{|c|}{56 dias } \\
\hline & $\begin{array}{c}\text { Tensão } \\
(\mathrm{MPa})\end{array}$ & Média & $\begin{array}{l}\text { Desvio } \\
\text { Padrão }\end{array}$ & $\begin{array}{l}\text { Tensão } \\
\text { (MPa) }\end{array}$ & Média & $\begin{array}{l}\text { Desvio } \\
\text { Padrão }\end{array}$ & $\begin{array}{c}\text { Tensão } \\
\text { (MPa) }\end{array}$ & Média & $\begin{array}{l}\text { Desvio } \\
\text { Padrão }\end{array}$ \\
\hline \multirow{3}{*}{$0 \%$} & 21,7 & \multirow{3}{*}{22,1} & \multirow{3}{*}{1,0} & 30,1 & \multirow{3}{*}{29,3} & \multirow{3}{*}{0,7} & 30,6 & \multirow{3}{*}{32,0} & \multirow{3}{*}{1,3} \\
\hline & 23,2 & & & 28,8 & & & 32,4 & & \\
\hline & 21,3 & & & 29,1 & & & 33,1 & & \\
\hline \multirow{3}{*}{$5 \%$} & 22,0 & \multirow{3}{*}{21,8} & \multirow{3}{*}{0,3} & 27,3 & \multirow{3}{*}{24,9} & \multirow{3}{*}{2,6} & 33,5 & \multirow{3}{*}{32,9} & \multirow{3}{*}{1,1} \\
\hline & 22,0 & & & 22,1 & & & 31,6 & & \\
\hline & 21,4 & & & 25,3 & & & 33,6 & & \\
\hline \multirow{3}{*}{$15 \%$} & 22,9 & \multirow{3}{*}{23,3} & \multirow{3}{*}{0,6} & 28,3 & \multirow{3}{*}{28,6} & \multirow{3}{*}{0,4} & 31,9 & \multirow{3}{*}{33,0} & \multirow{3}{*}{1,0} \\
\hline & 23,0 & & & 28,4 & & & 33,7 & & \\
\hline & 24,0 & & & 29,0 & & & 33,5 & & \\
\hline \multirow{3}{*}{$25 \%$} & 24,9 & \multirow{3}{*}{24,7} & \multirow{3}{*}{0,4} & 31,8 & \multirow{3}{*}{31,7} & \multirow{3}{*}{0,8} & 37,6 & \multirow{3}{*}{38,2} & \multirow{3}{*}{0,7} \\
\hline & 24,2 & & & 32,5 & & & 39,0 & & \\
\hline & 25,0 & & & 30,9 & & & 38,1 & & \\
\hline
\end{tabular}

Fonte: Elaborado pelos autores

Aos 7 dias, observa-se o aumento da resistência à compressão axial das amostras dos traços contendo $15 \%$ e $25 \%$ de cinza volante em relação ao traço referência (0\%). As amostras contendo 5\% de adição apresentaram redução em relação ao traço referência. Aos 28 dias, apenas o traço com $25 \%$ de adição de cinza volante apresentou incremento na resistência também em relação ao traço referência. Já aos 56 dias, todas as amostras contendo cinza volante aprimoraram essa característica, com destaque para as amostras com $25 \%$ de adição que obtiveram as maiores resistências. $\mathrm{O}$ aumento da resistência nas amostras contendo cinza volante já era esperado. No estudo de Hannesson $e t$ al. (2012), no qual foram utilizados diferentes teores de cinza volante nas amostras, já se tinha observado que as amostras com teores de até $25 \%$ de cinza volante aumentaram a resistência à compressão axial devido ao tamanho das partículas, onde obtém-se um empacotamento mais eficaz com material fino. Ortolan (2015) também destaca que a maior contribuição das pozolanas ocorre em idades elevadas, quando se tem a hidratação secundária das partículas de cinza volante, concordando com os resultados obtidos nesse programa experimental. 


\subsection{Ensaios de velocidade de propagação de ondas ultrassônicas}

Os resultados foram separados conforme a cura das amostras, observando o comportamento dos diferentes teores de cinza volante em relação ao ensaio de ultrassom em cada situação, aos 7 dias e aos 28 dias. Alguns traços apresentam menor número de amostras devido a ruptura no momento do ensaio.

\subsubsection{Amostras em cura em ambiente seco}

Os resultados de velocidade de propagação de ondas ultrassônicas das amostras mantidas em cura seca estão descritas na Tabela 4.

Tabela 4 - Resultados de velocidade de propagação de ondas ultrassônicas $(\mathrm{m} / \mathrm{s})$ com cura seca

\begin{tabular}{|c|c|c|c|c|c|c|}
\hline \multirow[b]{2}{*}{ Traço } & \multicolumn{6}{|c|}{ Velocidade de Propagação de Onda $(\mathrm{m} / \mathrm{s})$} \\
\hline & 7 dias & Média & $\begin{array}{l}\text { Desvio } \\
\text { Padrão }\end{array}$ & 28 dias & Média & $\begin{array}{l}\text { Desvio } \\
\text { Padrão }\end{array}$ \\
\hline \multirow{2}{*}{$0 \%$} & 4401 & \multirow{2}{*}{4298,5} & \multirow{2}{*}{145,0} & 4276 & \multirow{2}{*}{4188,0} & \multirow{2}{*}{124,5} \\
\hline & 4196 & & & 4100 & & \\
\hline \multirow{2}{*}{$5 \%$} & 4511 & \multirow{2}{*}{4456,0} & \multirow{2}{*}{77,8} & 4423 & \multirow{2}{*}{4385,5} & \multirow{2}{*}{53,0} \\
\hline & 4401 & & & 4348 & & \\
\hline \multirow{3}{*}{$15 \%$} & 4245 & \multirow{3}{*}{4280,7} & \multirow{3}{*}{107,1} & 4348 & \multirow{3}{*}{4344,7} & \multirow{3}{*}{26,2} \\
\hline & 4401 & & & 4369 & & \\
\hline & 4196 & & & 4317 & & \\
\hline \multirow{3}{*}{$25 \%$} & 4147 & \multirow{3}{*}{4244,3} & \multirow{3}{*}{137,0} & 4265 & \multirow{3}{*}{4355,7} & \multirow{3}{*}{78,5} \\
\hline & 4185 & & & 4401 & & \\
\hline & 4401 & & & 4401 & & \\
\hline
\end{tabular}

Fonte: Elaborado pelos autores

Neste tipo de cura, esperava-se esse tipo de comportamento, visto que os corpos de prova não tiveram contato direto com a água ou umidade considerável, situação a qual poderia ocorrer hidratação secundária. Não houve reação de autocura com a cinza volante, visto que o traço $0 \%$ não contém a cinza volante e o traço $5 \%$ contém muito pouco. Houve uma redução na velocidade dos 7 dias para os 28 dias nas amostras de $0 \%$.

Nos corpos de prova com traço contendo 5\% de cinza volante, obteve-se praticamente o mesmo comportamento que o traço anterior, com $0 \%$ de cinza volante. Isto evidencia que com esse percentual não houve contribuição relevante na densidade da matriz, não ocorrendo também o fechamento da fissura. Nos resultados obtidos com o traço de $15 \%$ de cinza volante, percebe-se que houve aumento em duas amostras. Houve um aumento considerável, tendo em vista que estavam expostas em cura seca, sem influência direta da água nas reações de autocura. Mesmo assim, aos 28 dias, praticamente permaneceu com o mesmo padrão de qualidade do concreto obtido aos 7 dias. Apesar de estar exposto em cura seca, as amostras de traço com adições de $25 \%$ de cinza volante obtiveram bons ganhos na velocidade de propagação das ondas ultrassônicas, com exceção de uma amostra que não obteve alteração.

Pode-se perceber que nos traços referência e com 5\% de cinza volante não ocorreu o acréscimo da velocidade de ondas ultrassônicas, o que se espera quando há maior desenvolvimento da resistência ao longo do tempo, conforme Pacheco (2016). Nos traços com $15 \%$ e $25 \%$, percebeu-se um desenvolvimento maior de velocidade de propagação, o que era esperado, uma vez que há um percentual maior de uso da pozolana, colaborando de modo mais expressivo com o ganho de resistência e consequente maior densificação da matriz. Como nos traços referência e com 5\% não houve alteração na velocidade verificada, não se atribui nenhum acréscimo a formação de produtos de autorregeneração.

\subsubsection{Amostras em cura na câmara úmida}

Os resultados de velocidade de propagação de ondas ultrassônicas das amostras mantidas em cura com câmara úmida estão descritas na Tabela 5. Nota-se que os valores das velocidades de propagação das ondas ultrassônicas de todas as amostras ficaram altos, inclusive, todas acima de $4500 \mathrm{~m} / \mathrm{s}$. Essa informação já demonstra que a presença da umidade 
direta nas amostras auxiliou em um maior desenvolvimento de resistência do concreto, através da hidratação secundária e as reações obtidas com o silicato de cálcio hidratado.

Tabela 5 - Resultados de velocidade de propagação de ondas ultrassônicas $(\mathrm{m} / \mathrm{s})$ com cura em câmara úmida

\begin{tabular}{|c|c|c|c|c|c|c|}
\hline \multirow{2}{*}{ Traço } & \multicolumn{6}{|c|}{ Velocidade de Propagação de Onda (m/s) } \\
\hline & 7 dias & Média & Desvio Padrão & 28 dias & Média & Desvio Padrão \\
\hline \multirow{3}{*}{$0 \%$} & 4627 & \multirow{3}{*}{4647,3} & \multirow{3}{*}{35,2} & 4688 & \multirow{3}{*}{4628,0} & \multirow{3}{*}{59,5} \\
\hline & 4627 & & & 4569 & & \\
\hline & 4688 & & & 4627 & & \\
\hline \multirow{2}{*}{$5 \%$} & 4627 & \multirow{2}{*}{4569} & \multirow{2}{*}{82,0} & 4688 & \multirow{2}{*}{4616,5} & \multirow{2}{*}{101,1} \\
\hline & 4511 & & & 4545 & & \\
\hline \multirow{3}{*}{$15 \%$} & 4348 & \multirow{3}{*}{4420} & \multirow{3}{*}{83,1} & 4455 & \multirow{3}{*}{4511,7} & \multirow{3}{*}{57,0} \\
\hline & 4511 & & & 4569 & & \\
\hline & 4401 & & & 4511 & & \\
\hline \multirow{2}{*}{$25 \%$} & 4455 & \multirow{2}{*}{4541} & \multirow{2}{*}{121,6} & 4604 & \multirow{2}{*}{4615,5} & \multirow{2}{*}{16,3} \\
\hline & 4627 & & & 4627 & & \\
\hline
\end{tabular}

Fonte: Elaborado pelos autores

Nota-se que os valores das velocidades de propagação das ondas ultrassônicas de todas as amostras ficaram altos, inclusive, todas acima de $4500 \mathrm{~m} / \mathrm{s}$. Essa informação já demonstra que a presença da umidade direta nas amostras auxiliou em um maior desenvolvimento de resistência do concreto, através da hidratação secundária e as reações obtidas com o silicato de cálcio hidratado.

Os resultados das amostras de traço $0 \%$ demonstram que a hidratação secundária do cimento, através da umidade da câmara úmida, não impactou as amostras, que não apresentaram acréscimo entre as idades. As amostras do traço de 5\% de cinza volante obtiveram aumento na velocidade de propagação das ondas ultrassônicas. Isso evidencia que a umidade da câmara teve influência sobre as amostras, porém, muito pouco, tendo em vista outros resultados deste estudo. Esse acréscimo pode ter sido influenciado tanto pela hidratação secundária das partículas anidras de cimento, como pelas reações de formação de produtos de autorregeneração. As amostras de $15 \%$ de cinza volante, diferente das amostras de $0 \%$ e 5\%, obtiveram um resultado mais expressivo. Ocorreu o aumento da velocidade de propagação de ondas ultrassônicas nas três amostras. Valores bem consideráveis e que podem ser um indício da ocorrência de reações de autorregeneração do concreto. Vale ressaltar que os resultados obtidos no ensaio da amostra de $25 \%$ foram superiores, já evidenciando o melhor empacotamento que a cinza volante produz no concreto. Percebeu-se que uma amostra se manteve com o mesmo resultado, o qual já era elevado.

\subsubsection{Amostras em cura submersa}

Os resultados velocidade de propagação de ondas ultrassônicas das amostras mantidas em cura submersa estão descritas na Tabela 6.

Tabela 6 - Resultados de velocidade de propagação de ondas ultrassônicas $(\mathrm{m} / \mathrm{s})$ com cura submersa em água

\begin{tabular}{|c|c|c|c|c|c|c|}
\hline \multirow[b]{2}{*}{ Traço } & \multicolumn{6}{|c|}{ Velocidade de Propagação de Onda $(\mathrm{m} / \mathrm{s})$} \\
\hline & 7 dias & Média & $\begin{array}{l}\text { Desvio } \\
\text { Padrão } \\
\end{array}$ & 28 dias & Média & $\begin{array}{l}\text { Desvio } \\
\text { Padrão }\end{array}$ \\
\hline $0 \%$ & 4627 & 4627 & 0 & 4688 & 4688 & 0 \\
\hline \multirow{3}{*}{$5 \%$} & 4688 & \multirow{3}{*}{4648,3} & \multirow{3}{*}{68,7} & 4511 & \multirow{3}{*}{4533,7} & \multirow{3}{*}{19,6} \\
\hline & 4569 & & & 4545 & & \\
\hline & 4688 & & & 4545 & & \\
\hline \multirow{3}{*}{$15 \%$} & 4401 & \multirow{3}{*}{4437} & \multirow{3}{*}{31,2} & 4545 & \multirow{3}{*}{4600,0} & \multirow{3}{*}{53,1} \\
\hline & 4455 & & & 4651 & & \\
\hline & 4455 & & & 4604 & & \\
\hline \multirow{2}{*}{$25 \%$} & 4455 & \multirow{2}{*}{4541} & \multirow{2}{*}{121,6} & 4604 & \multirow{2}{*}{4633,5} & \multirow{2}{*}{41,7} \\
\hline & 4627 & & & 4663 & & \\
\hline
\end{tabular}

Fonte: Elaborado pelos autores 
Em cura submersa, espera-se maior contribuição do ganho de resistência, uma vez que a condição proporcionar a reação secundária e a formação de produtos de regeneração. Pelo traço referência, concluiu-se que, pelo fato de não haver teores de cinza no concreto, ocorreu um aumento sutil devido à hidratação de partículas de cimento anidro.

Nas amostras com 5\% de cinza volante, observou-se uma redução nos resultados do ensaio de ultrassom, podendo ser oriunda de alguma variação no teor de umidade da amostra, por exemplo. O resultado das amostras do traço com $15 \%$ de cinza volante demonstrou grande aumento das velocidades de propagação das ondas ultrassônicas. Foram obtidos aumentos de 150 a 200 m/s. Essa maior densificação percebida na amostra pode ser oriunda da reação da cinza volante com o silicato de cálcio hidratado, o que gerou autorregeneração da fissura. Ainda, nas amostras de $25 \%$ os resultados apontaram novamente para acréscimo na velocidade de propagação de ondas ultrassônicas, quase $150 \mathrm{~m} / \mathrm{s} \mathrm{de} \mathrm{acréscimo.}$ Como já citado, a maior densificação pode decorrer da cicatrização de pequenas fissuras no material, ou da hidratação tardia das pozolanas. Conforme Tutikian e Dal Molin (2011), o aumento da resistência à compressão assim como a velocidade de propagação de ondas já era esperado ao utilizar cinza volante, principalmente em idades avançadas.

\subsection{Ensaios de Imagem em Microscópio Ótico}

Foram registradas imagens com câmera fotográfica simples, e tais amostras, por tratamento de imagem, tiveram suas fissuras mensuradas. Após, na idade de 120 dias, foram utilizadas as amostras do microscópio de alta precisão para mensurar suas dimensões e o consequente percentual das fissuras cicatrizado.

\subsubsection{Amostras referência - $0 \%$ de cinza volante}

A Tabela 7 apresenta a mensuração das fissuras nas amostras referência com as diferentes condições de cura.

Tabela 7 - Mensuração de fissuras do traço referência ( $0 \%$ de cinza volante).

\begin{tabular}{|c|c|c|c|}
\hline \multirow{2}{*}{ Cura } & \multicolumn{2}{|c|}{ Fissura $(\mathrm{mm})$} & \multirow{2}{*}{$\begin{array}{c}\text { Percentual } \\
\text { Cicatrizado (\%) }\end{array}$} \\
\cline { 2 - 3 } & Abertura inicial & Abertura final & Cicin \\
\hline Submersa & 0,32 & 0,23 & 28,53 \\
\hline \multirow{3}{*}{ Úmida } & 0,20 & 0,18 & 8,00 \\
\cline { 2 - 3 } & 0,13 & 0,00 & 100,00 \\
\cline { 2 - 3 } Seca & 0,24 & 0,21 & 13,46 \\
\cline { 2 - 3 } & 0,24 & 0,24 & 0,75 \\
\hline \multirow{2}{*}{ Senn } & 0,40 & 0,38 & 4,35 \\
\hline
\end{tabular}

Fonte: Elaborado pelos autores

Percebe-se o maior percentual de cicatrização das fissuras nas amostras em cura úmida e submersa. Como estas são as amostras referência, sem uso de cinza volante, esse fechamento de fissura se deve a hidratação secundária das partículas de cimento anidro. Destaque para a amostra com cura em câmara úmida, representada na Figura 2, a qual apresentou indícios de cicatrização completa, e para a amostra com cura submersa, que possuía a maior fissura dessas amostras e obteve fechamento de $28,53 \%$. A amostra com cura seca não obteve resultados significativos de cicatrização, mantendose praticamente com as mesmos tamanhos de fissuras.

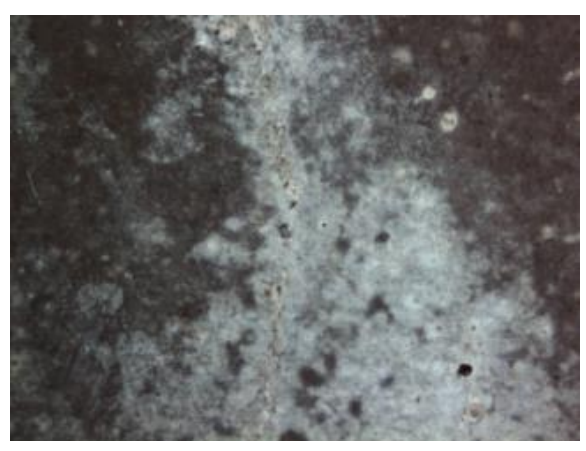

Figura 2: Fechamento completo da fissura com produto de hidratação 
Percebe-se que houve a influência esperada das condições de cura na autorregeneração do concreto. Já nas amostras curadas em condição seca, como já havia sido previsto por Van Tittelboom et al. (2016), não houve cicatrização e fechamento das fissuras. Destaca-se que as amostras apresentadas nesse item não continham pozolana, portanto, a cicatrização ocorrida deve ser atribuida a própria utilização do cimento no traço.

\subsubsection{Amostras contendo 5\% de cinza volante}

A Tabela 8 apresenta a mensuração das fissuras em amostras com 5\% de cinza volante com as diferentes condições de cura.

Tabela 8 - Mensuração de fissuras do traço com 5\% de cinza volante.

\begin{tabular}{|c|c|c|c|}
\hline Cura & $\begin{array}{c}\text { Fissuração } \\
\text { inicial (mm) }\end{array}$ & $\begin{array}{c}\text { Fissuração } \\
\text { final (mm) }\end{array}$ & $\begin{array}{c}\text { Percentual } \\
\text { Cicatrizado (\%) }\end{array}$ \\
\hline \multirow{3}{*}{ Submersa } & 0,12 & 0,00 & 100,00 \\
\cline { 2 - 4 } & 0,14 & 0,10 & 27,50 \\
\cline { 2 - 4 } & 0,20 & 0,14 & 29,95 \\
\hline \multirow{2}{*}{ Úmida } & 0,12 & 0,00 & 100,00 \\
\cline { 2 - 4 } & 0,15 & 0,00 & 100,00 \\
\hline \multirow{2}{*}{ Seca } & 0,20 & 0,17 & 13,75 \\
\cline { 2 - 4 } & 0,23 & 0,22 & 3,09 \\
\hline
\end{tabular}

Fonte: Elaborado pelos autores

Comparando as amostras apresentadas com 5\% de adição de cinza volante, as amostras de câmara úmida foram mais eficientes que as demais, com o fechamento das fissuras de duas amostras. Na cura seca, novamente, não obtiveram-se resultados significativos. Na cura submersa, apenas uma amostra obteve fechamento total da fissura, demonstrando que a presença direta de água não garante a hidratação secundária de partículas de cimento anidras ou nas reações com silicato de cálcio hidratado com a pozolana. Com $5 \%$ de cinza volante, a cicatrização máxima foi de $0,15 \mathrm{~mm}$, observado nas amostras de cura úmida, sendo superior ao traço referência. A Figura 3, mostra um comparativo de imagens de uma amostra da cura em câmara úmida, aos 7 dias e aos 120 dias, a qual obteve fechamento total da fissura. Esse comportamento, de cicatrização superior em amostras submetidas à câmara úmida já foi retratado na bibliografia por Reinhardt e Jooss (2003).

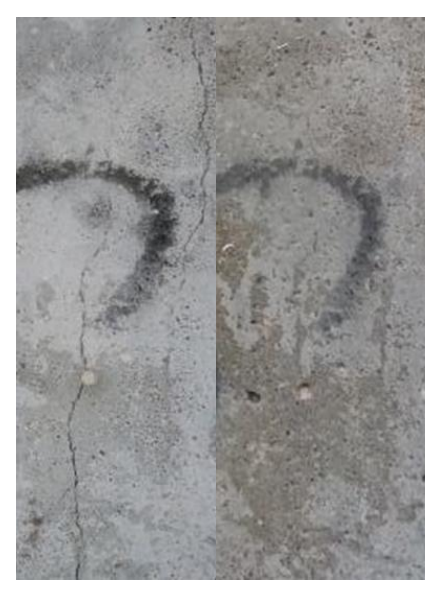

Figura 3: Imagens comparativas da amostra aos 7 dias e aos 120 dias.

\subsubsection{Amostras contendo $15 \%$ de cinza volante}

A Tabela 9 apresenta a mensuração das fissuras em amostras contendo $15 \%$ de cinza volante com as diferentes condições de cura. 
Tabela 9 - Mensuração de fissuras do traço com 15\% de cinza volante.

\begin{tabular}{|c|c|c|c|}
\hline Cura & $\begin{array}{c}\text { Fissuração } \\
\text { inicial (mm) }\end{array}$ & $\begin{array}{c}\text { Fissuração } \\
\text { final (mm) }\end{array}$ & $\begin{array}{c}\text { Percentual } \\
\text { Cicatrizado (\%) }\end{array}$ \\
\hline \multirow{3}{*}{ Submersa } & 0,31 & 0,23 & 27,00 \\
\cline { 2 - 4 } & 0,29 & 0,17 & 40,00 \\
\cline { 2 - 4 } & 0,28 & 0,22 & 23,00 \\
\hline \multirow{2}{*}{ Úmida } & 0,23 & 0,21 & 10,30 \\
\cline { 2 - 4 } & 0,24 & 0,21 & 11,58 \\
\hline \multirow{3}{*}{ Seca } & 0,20 & 0,19 & 5,35 \\
\cline { 2 - 4 } & 0,27 & 0,23 & 15,78 \\
\cline { 2 - 4 } & 0,31 & 0,28 & 9,68 \\
\hline
\end{tabular}

Fonte: Elaborado pelos autores

Novamente, nas medições das amostras com $15 \%$ de cinza volante, destacaram-se as amostras expostas a cura submersa, as quais obtiveram até $40 \%$ de fechamento das fissuras. Isso demonstra que, com $15 \%$ de cinza volante, a cura submersa foi mais eficiente nas reações de cicatrização.

Analisando os resultados obtidos, nota-se que a cura submersa foi mais eficiente em maiores quantidades de cinza volante. Outro fator notável, e que pode ter tido influência sobre os resultados, é o tamanho das fissuras. Nota-se que as amostras expostas a cura em câmara úmida, que possuem fissuras abaixo de 0,2 mm, demonstram seus resultados mais expressivos, sendo até mais eficiente que a cura submersa. Em contrapartida, a cura submersa demonstra muito mais eficiência nos seus resultados em amostras com fissuras em torno de 0,3 mm. Percebe-se que, mesmo com $15 \%$ de cinza volante, não há reação de autorregeneração em cura seca, devido a falta de umidade neste tipo de cura.

\subsubsection{Amostras contendo $25 \%$ de cinza volante}

Consta na Tabela 10 a mensuração das fissuras em amostras com 25\% de cinza volante e diferentes condições de cura.

Tabela 10 - Mensuração de fissuras do traço com $25 \%$ de cinza volante.

\begin{tabular}{|c|c|c|c|}
\hline Cura & $\begin{array}{c}\text { Fissuração } \\
\text { inicial (mm) }\end{array}$ & $\begin{array}{c}\text { Fissuração } \\
\text { final }(\mathrm{mm})\end{array}$ & $\begin{array}{c}\text { Percentual } \\
\text { Cicatrizado }(\%)\end{array}$ \\
\hline \multirow{2}{*}{ Submersa } & 0,29 & 0,20 & 29,79 \\
\cline { 2 - 4 } & 0,28 & 0,20 & 29,96 \\
\hline \multirow{2}{*}{ Úmida } & 0,20 & 0,12 & 41,15 \\
\cline { 2 - 4 } & 0,32 & 0,25 & 20,00 \\
\hline \multirow{3}{*}{ Seca } & 0,28 & 0,26 & 8,50 \\
\cline { 2 - 4 } & 0,25 & 0,22 & 11,88 \\
\cline { 2 - 4 } & 0,25 & 0,24 & 5,00 \\
\hline
\end{tabular}

Fonte: Elaborado pelos autores

Os resultados das amostras de $25 \%$ de cinza volante novamente destacaram a necessidade de atmosfera úmida ou submersa para ocorrência da regeneração, o que já foi demonstrado nos estudos de Zhang et al (2017), por exemplo. Considerando a cura submersa em água, comparando os diferentes traços, não se obteve diferenças significativas na relação do traço referência com os demais traços com adição de cinza volante. Pode ter ocorrido uma mesma magnitude de cicatrização mesmo que através de processos diferentes no material. Considerando a cura em câmara úmida, percebe-se que esta cura tem grande influência sobre amostras com fissuras até $0,2 \mathrm{~mm}$. Analisando a cura seca, praticamente nenhuma amostra gerou resultados de cicatrização das fissuras, evidenciando que este tipo de cura não favorece as reações de autorregeneração. Reddy e Ravitheja (2019) já haviam apontado esse tipo de cura como ineficaz para gerar produtos de cicatrização nos concretos.

Tendo em vista tudo que foi analisado e os resultados obtidos através das imagens das fissuras, bem como as medidas feitas para realização das analises, observa-se que a influência da cinza volante no fechamento de fissuras é praticamente o mesmo se comparado com a hidratação secundária de partículas anidras de cimento, em amostras de até $0,3 \mathrm{~mm}$, sendo desnecessário o uso da cinza volante visando somente o fechamento das fissuras. 


\section{CONSIDERAÇÕES FINAIS}

De acordo com os resultados analisados com relação à influência dos diferentes teores de cinza volante na resistência do concreto, constatou-se que a adição do material não impactou esse parâmetro nas idades iniciais ( 7 e 28 dias). Já aos 56 dias, apenas as amostras com adição de $25 \%$ de cinza volante obtiveram resultados significativos em relação ao traço referência. Como Hannesson et al (2012) já havia observado, as maiores quantidades de adições tendem a aumentar a resistência, porém há um limite de adição fixado em $40 \%$, pois a mistura chega ao seu limite de $\mathrm{CaO}$.

Em relação à influência dos diferentes teores na capacidade de autorregenerar o concreto, percebeu-se pelo ensaio de velocidade de propagação de ondas ultrassônicas, que houve impacto. O traço referência apresentou menores velocidades nos resultados das amostras em cura seca aos 7 dias, evidenciando reações de empacotamento e densificação da matriz das demais amostras com adição de cinza volante. Já na cura úmida e na submersa, o comportamento das amostras referência se mostraram tão eficientes quanto as com adições, aumentando significativamente a velocidade de propagação de ondas ultrassônicas. Esse resultado mostra que a hidratação secundária das partículas de cimento anidra foi tão eficiente quanto as reações de autorregeneração das amostras com adições, elevando a qualidade do concreto.

Ao analisar o potencial de fechamento das fissuras com ensaios de caracterização por imagem, constatou-se que o potencial máximo encontrado de fechamento das fissuras foi de $0,15 \mathrm{~mm}$. Amostras com fissuras maiores não obtiveram fechamento total da fissura. As amostras de cura seca se mantiveram praticamente com as mesmas medidas.

No que se refere a verificação do impacto de diferentes condições de cura na capacidade de autorregeneração dos traços propostos de concreto, as amostras em cura seca não obtiveram evolução com relação ao fechamento das fissuras. Como ponto favorável na cura seca, as amostras com adição de $15 \%$ e $25 \%$ de cinza volante não tiveram redução da velocidade de propagação de ondas ultrassônicas, apresentando um aumento significativo. Em relação a cura em câmara úmida, observou-se que foi eficiente nas reações de densificação da matriz, obtendo aumento nos resultados de ultrassom. Nas caracterizações de imagem, ficou notável a capacidade de fechamento das fissuras de amostras com abertura de até $0,2 \mathrm{~mm}$, porém para fissuras maiores, este tipo de cura não obteve resultados satisfatórios. A cura submersa foi a que obteve melhor resultado nos ensaios de ultrassom.

\section{REFERENCIAS}

AFIFUDIN, H; NADZARAH, W; HAMIDAH M.; NOOR HANA H.B. Microbial Participation in the Formation of Calcium Silicate Hydrated (CSH) from Bacillus subtilis, The 2nd International Building Control Conference, p159 $165,2011$.

ALYOUSIF, A. Self- healing capability of engineered cementitious composites incorporating different types of pozzolanic materials. Ryerson University. Doctor of philosophy- Civil Engineering, Toronto, Ontario, Canada, 2016

ARNOLD, D. SELF-HEALING CONCRETE. INGENIA ISSUE, $\mathrm{n}$ 46. March, 2011, p39-43.

ASSOCIAÇÃO BRASILEIRA DE NORMAS TÉCNICAS - ABNT. NBR 12655:2015. Concreto de cimento Portland — Preparo, controle, recebimento e aceitação — Procedimento. Rio de Janeiro, 2015.

ASSOCIAÇÃO BRASILEIRA DE NORMAS TÉCNICAS - ABNT. NBR 15575:2013. Edificações Habitacionais Desempenho. Brasília, 2013.

ASSOCIAÇÃO BRASILEIRA DE NORMAS TÉCNICAS - ABNT. NBR 5738:2015. Concreto - Procedimento para moldagem e cura de corpos de prova, Rio de Janeiro, 2015.

ASSOCIAÇÃO BRASILEIRA DE NORMAS TÉCNICAS - ABNT. NBR 5739:2018. Concreto - Ensaio de compressão de corpos de prova cilíndricos, Rio de Janeiro, 2018.

ASSOCIAÇÃO BRASILEIRA DE NORMAS TÉCNICAS - ABNT. NBR 6118:2014. Projeto de Estruturas de Concreto - Procedimento. Rio de Janeiro, 2014. 
BONIĆ, Z. et al. Damage of concrete and reinforcement of reinforced-concrete foundations caused by environmental effects. Procedia Engineering, v. 117, n. 1, p. 416-423, 2015.

CORSINI, R.. Trinca ou fissura?. Revista Techne, 160. ed. São Paulo. Ed. Pini, 2010. Disponível em: <http://techne17.pini.com.br/engenharia-civil/160/trinca-ou-fissura-como-se-originam-quais-os-tipos-285488-1.aspx> Acesso em: 08 de dezembro de 2017.

FLORES, M.G; MOSCATO, M; SERNA, P; FERRARA, L. Self-healing capability of concrete with crystalline admixtures in different environments. Construction and building materials, 86, 2015, 1-11.

GJØRV, Odd E. Durability of Concrete Structures, Boca Raton, p151-172, 2011.

GRUYAERT, E. et al. Activation of Pozzolanic and Latent-Hydraulic Reactions by Alkalis in Order to Repair Concrete Cracks. Journal of Materials in Civil Engineering, v. 27, n. 7, p. 401-428, 2014.

HAGER, M D. et al. Self-Healing Materials. Materials Views, Ed. 22, p. 5424-5430, 2010.

HANNESSON, G. et al. The influence of high volume of fly ash and slag on the compressive strength od selfconsolidating concrete. Construction and Building Materials, Maio, 2012. v. 30, p. 161-168.

HAVLÁSEK, P. et al. Thermo-mechanical simulations of early-age concrete cracking with durability predictions. IOP Conference Series: Materials Science and Engineering, v. 236, n. 1, 2017.

HELENE, P.; ANDRADE, J. J. de O.; MEDEIROS, M. H. F. de Durabilidade e Vida Útil das Estruturas de Concreto, São Paulo: IBRACON, 2011. Cap. 22.

HUANG, H. et al. Self-healing in cementitious materials: Materials, methods and service conditions. Materials and Design, v. 92, p. 499-511, 2016.

IS 13311: Non-destructive testing of concrete - Methods of Test - Part 1: Ultrasonic pulse velocity. New Delhi: Bureau Of Indian Standards, 1992.

ISAIA, Geraldo C. (Ed.) Concreto: Ensino, Pesquisa e Realizações. São Paulo: IBRACON, 2005. 2 v. 1.600 p.

JONKERS, H. M. Bacteria-based self-healing concrete. Delf, The Netherlands: Delf University of Technology, Faculty of Civil Engineering and GeoSciences, Departament of Materials and Enviroment, 2011.

KHALIQ, W.; EHSAN, M. B. Crack healing in concrete using various bio influenced self-healing techniques. Construction and Building Materials, v. 102, p. 349-357, 2016.

KRISHNAPRIYA, S.; VENKATESH BABU, D. L.; G., P. A. Isolation and identification of bacteria to improve the strength of concrete. Microbiological Research, v. 174, p. 48-55, 2015.

KUMAR, B.; et al. Evaluation of properties of high-volume fly-ash concrete for pavements. Journal of materials in civil engineering, v. 19, p. 906-911, 2007.

LENG, F. et al. An experimental study on the properties of resistance to diffusion of chloride ions of fly ash and blast furnace slag concrete. Cement and Concrete Research, v. 30, p. 989-992, 2000.

LIU, J. et al. Permeation Properties and Pore Structure of Surface Layer of Fly Ash Concrete. Materials, v.7, n.6, p. 4282-4296, 2014.

MEHTA, P. Kumar; MONTEIRO, Paulo J. M.. Concreto: Microestrutura, Propriedades e Materiais. 4. ed. São Paulo. Ed. Pini, 2014.

NEVILLE, Adam M. Propriedades do Concreto. 5. ed. Porto Alegre: Bookman, 2016. 
ORTOLAN, Vinicius de Kayser. Avaliação da influência do pH e da força iônica da solução dos poros do concreto na resistência à corrosão da armadura. 2015. 128 f. Dissertação (Mestrado) - Programa de Pós-graduação em Engenharia Civil, Universidade do Vale do Rio dos Sinos, São Leopoldo, 2015.

PACHECO, Fernanda. Investigação da relação entre os parâmetros de projeto das estruturas de concreto armado visando à durabilidade, 2016. 185 f. Dissertação (Mestrado) - Universidade do Vale do Rio dos Sinos, Programa de Pós-Graduação em Engenharia Civil, São Leopoldo, RS, 2016.

POSSAN, E.; DEMOLINER, Carlos A., Desempenho, Durabilidade e Vida Útil das Edificações: Abordagem Geral. Rio Grande do Sul, 2010.

REDDY, T. C. S.; RAVITHEJA, A. Macro mechanical properties of self healing concrete with crystalline admixture under different environments. Ain Shams Engineering Journal, v. 10, n. 1, p. 23-32, 2019.

REINHARDT, H. W.; JOOSS, M. Permeability and self-healing of cracked concrete as a function of temperature and crack width. Cement and Concrete Research, v. 33, p. 981-985, 2003.

SANGADJI, S. Can Self-healing Mechanism Helps Concrete Structures Sustainable? Procedia Engineering, v. 171, p. 238-249, 2017.

SANGADJI, S. et al. The Use of Alkaliphilic Bacteria-based Repair Solution for Porous Network Concrete Healing Mechanism. Procedia Engineering, v. 171, p. 606-613, 2017.

SANKAVANARAYANNAN, S.; JAGADESAN, J. Comparison of high performance fly ash concrete using nano silica fume on different mixes. Circuits and Systems, v. 7, p. 1259-1267, 2016.

SOUZA, V. C. M.; RIPPER, T. Patologia, recuperação e recuperação de estruturas de concreto. São Paulo: PINI, 2001.

TAN, N.P.B.; KEUNG, L.H.; CHOI, W.H.; LAM, W.C.; LEUNG, H.N, Silica-based self-healing microcapsules for self-repair in concrete, Journal of Applied Polymer Science, 2015.

TANG, S. W. et al. Recent durability studies on concrete structure. Cement and Concrete Research, v. 78, p. 143$154,2015$.

TANG, W.; KARDANI, O; CUI, H. Robust evaluation of self-healing efficiency in cementitious materials - A review. Construction and Building Materials, v. 81, p. 233-247, 2015.

THOMAZ, E.. Trincas em edifícios: causas, prevenção e recuperação. 192p. São Paulo, 1985. Dissertação (Pósgraduação em Engenharia Civil) - Escola Politécnica, Universidade de São Paulo, São Paulo, 1985.

TITTELBOOM, K. V. et al. Comparison of different approaches for self-healing concrete in large-scale lab test. Construction and Building Materials, Ed. 107, 2016, p. 125-137.

TUTIKIAN, B. F.; DAL MOLIN, D. Comparativo das propriedades do concreto autoadensável (CAA) utilizando areia fina e cinza volante. Revista IBRACON de Estruturas e Materiais, v.4, p. 247-276, 2011.

VARLAMOV, A. A.; SHAPOVALOV, E. L.; GAVRILOV, V. B. Estimating Durability of Reinforced Concrete. IOP Conference Series: Materials Science and Engineering, v. 262, p. 1-7, 2017.

ZHANG, J.L. et al. A binary concrete crack self-healing system containing oxygen-releasing tablet and bacteria and its Ca2+-precipitation performance, 2016.

ZHANG, J. et al. Immobilizing bacteria in expanded perlite for the crack self-healing in concrete. Construction and Building Materials, v. 148, p. 610-617, 2017. 